This item was submitted to Loughborough's Research Repository by the author.

Items in Figshare are protected by copyright, with all rights reserved, unless otherwise indicated.

\title{
Transmission efficiency and noise, vibration and harshness refinement of differential hypoid gear pairs
}

PLEASE CITE THE PUBLISHED VERSION

http://dx.doi.org/10.1177/1464419313496559

\section{PUBLISHER}

Sage ( Institution of Mechanical Engineers

VERSION

AM (Accepted Manuscript)

\section{PUBLISHER STATEMENT}

This work is made available according to the conditions of the Creative Commons Attribution-NonCommercialNoDerivatives 4.0 International (CC BY-NC-ND 4.0) licence. Full details of this licence are available at: https://creativecommons.org/licenses/by-nc-nd/4.0/

\section{LICENCE}

CC BY-NC-ND 4.0

\section{REPOSITORY RECORD}

Mohammadpour, Mahdi, Stephanos Theodossiades, and Homer Rahnejat. 2019. "Transmission Efficiency and Noise, Vibration and Harshness Refinement of Differential Hypoid Gear Pairs". figshare. https://hdl.handle.net/2134/14290. 


\title{
Transmission efficiency and NVH refinement of differential hypoid gear pairs
}

\author{
M. Mohammadpour ${ }^{1}$, S. Theodossiades ${ }^{1}$, H. Rahnejat ${ }^{1 *}$ and P. Kelly ${ }^{2}$ \\ ${ }^{1}$ Wolfson School of Mechanical and Manufacturing Engineering, Loughborough University, \\ Loughborough, UK \\ ${ }^{2}$ Ford Werke GmbH, Cologne, Germany \\ * Corresponding Author: H.Rahnejat@Lboro.ac.uk
}

\begin{abstract}
:
This paper presents a combined multi-body dynamics and lubricated contact mechanics model of vehicular differential hypoid gear pairs, demonstrating the transient nature of transmission efficiency and Noise, Vibration and Harshness (NVH) performance under various driving conditions. The contact of differential hypoid gears is subjected to mixed thermoelastohydrodynamic regime of lubrication. The coefficient of friction is obtained using an analytical approach for non-Newtonian lubricant shear and supplemented by boundary interactions for thin films. Additionally, road data and aerodynamic effects are used in the form of resisting torque applied to the output side of the gear pair. Sinusoidal engine torque variation is also included to represent engine order torsional input resident on the pinion gear. Analysis results are presented for New European Driving Cycle (NEDC) transience from low speed city driving condition in 2nd gear to steady state cruising in $4^{\text {th }}$ gear for a light truck. It is shown that the NEDC cycle captures the transmission efficiency characteristics of the differential hypoid gear pair under worst case scenario, with its underlying implications for fuel efficiency and emissions. However, it fails to address the other key attribute, being the NVH performance. In the case of Hypoid gears the resultant NVH characteristics can be particularly annoying. It is concluded that broader transient manoeuvres, encompassing NEDC are required for assessment, in order to obtain a balanced approach for transmission efficiency and NVH performance. This approach is undertaken in the paper, which is not hitherto reported in literature.
\end{abstract}

Keywords - Multi-body dynamics, Differential hypoid gears, Transmission efficiency, NVH 


\section{Introduction}

The high load carrying capacity, usually required of the final drive, constitutes partially conforming meshing teeth pairs at relatively high loads. This requirement brings about the use of hypoid gear pair geometry, which presents gradual changes in the geometry of an elliptical contact footprint between the teeth flanks. Therefore, since the inception of the automobile, the differential hypoid gear pairs with their orthogonal axes have become the final drive feature in all vehicles. They are one of the most important elements of the drive train system, particularly in the current trend towards better fuel efficiency, enhanced power and improved NVH refinement.

Most research works on gearing systems are dedicated to the dynamics of parallel axis transmissions, with only limited investigations reported for the dynamics of non-parallel axes gears, such as hypoid and bevel gears [1-5]. This dearth of analysis has been due to the complexity of their contact kinematics and meshing characteristics.

The hypoid gear teeth pairs form elliptical contact footprints and are often subjected to high loads of the order of several $\mathrm{kN}$, particularly in the case of commercial vehicles. The regime of lubrication is usually elastohydrodynamic with a thin film of lubricant being crucial for reducing friction, thus providing enhanced transmission efficiency and reduced $\mathrm{NVH}$ [6, 7]. NVH refinement is increasingly regarded by vehicle customers as a key attribute, particularly with regard to disconcerting noises, such as transmission rattle $[8,9]$, axle whine $[6,10,11]$ and the metallic high frequency clonk phenomenon in rear wheel drive vehicles [12, 13]. The high frequency $\mathrm{NVH}$ responses require the inclusion of component flexibility into the impulsive transient analysis [13].

Thus far, most reported dynamic models consider dry contact analysis, which is an unrealistic assumption with regards to the estimation of friction. A recent work by Karagiannis et al [6] presented a dynamic model of hypoid gears, focusing on the torsional vibrations of a differential gear pair under realistic loading conditions. They considered a quasi-static analytical elastohydrodynamic lubrication (EHL) analysis, taking into account the non-Newtonian shear of thin lubricant films and generated heat, thus estimating contact friction. They also included the 
effect of dynamic transmission error (DTE). A more detailed numerical solution for the lubricated contact with the resultant transmission efficiency is provided by Mohammadpour et al [7].

The main difficulty in the study of EHL of hypoid gears is their complex meshing geometry, which is obtained in both [6] and [7] using tooth contact analysis [14-16]. This approach is applied, using the CALYX commercial software [17]. In order to study the dynamics of the gear pair, realistic data, particularly estimation of the dynamic load is required $[6,7]$.

This paper presents a multi-body dynamics model of differential hypoid gear pairs, demonstrating the interactions between gear pair dynamics and NVH with friction in the elastohydrodynamic teeth pair conjunctions during meshing. The multi-body model comprises a two-degree of freedom torsional model developed in the ADAMS multi-body environment. The coefficient of friction is calculated using the available analytical formulae for thin non-Newtonian films in lubricated conjunctions. Additionally, road data and aerodynamic effects are included in the form of resistance applied to the output side of the gear pair (i.e. originating from the road wheels). The usual sinusoidal variation in engine torque (as the result of engine order vibrations) is also included in the model [6].

A thin lubricant film is formed during most of the meshing cycle [7]. Thus, mixed regime of lubrication is prevalent. The Greenwood and Tripp [18] model is used to take into account the effect of any interactions of the ubiquitous asperities on the contiguous contacting meshing teeth surfaces. The film thickness and inefficiency have been calculated in conjunction with gear dynamics and the NVH behaviour of the gear pair. The study integrates the tribological efficiency of hypoid gears with multi-body dynamics of the final drive system, incorporating road wheel traction and vehicle inertial dynamics. The main contribution of this paper is development of a combined dynamics and tribological model in order to take into account the interactions between key differential system attributes. These are NVH refinement and efficiency. This approach has not been hitherto reported in literature.

\section{Model Description}


The multi-body model comprises a two-degrees of freedom torsional model of the drive train system, developed in the ADAMS multi-body environment (figure 1). The inertial properties of the mating gear pair are listed in table 1. The values of inertia include different parts of the transmission system, such as the retaining shafts; driveline and rear axle, in addition to the hypoid gears themselves. The list of constraints, used in the multi-body model is given in table 2 .

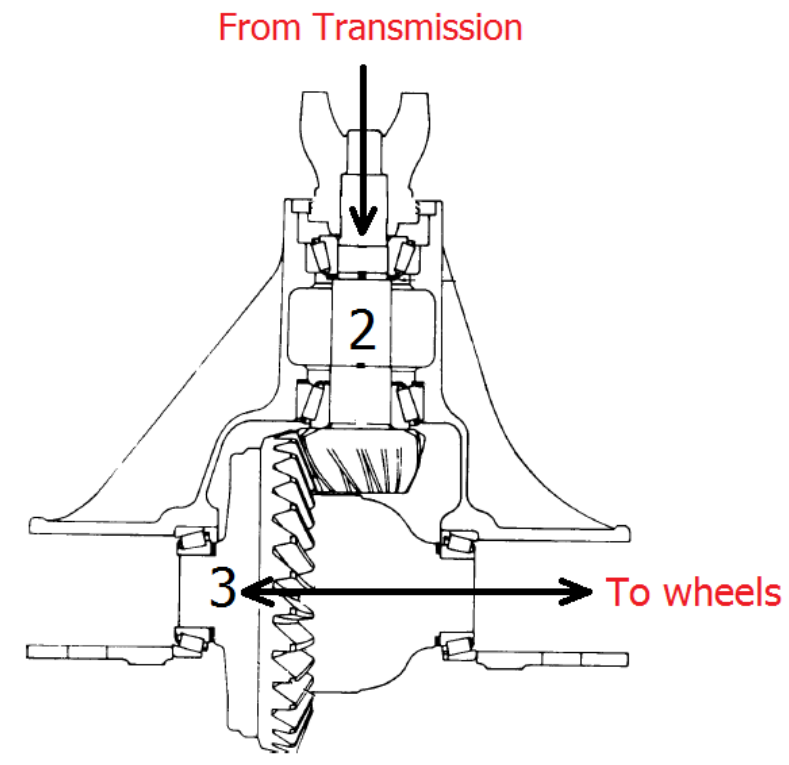

Figure 1: An overview of the multi-body dynamics model

Table 1: Inertial part list

\begin{tabular}{|l|c|l|}
\hline Part number & Part name & Inertia $\left[\mathrm{kg} \mathrm{m}^{2}\right]$ \\
\hline 1 & Ground & ----- \\
\hline 2 & Pinion & $1734 \cdot 10^{-6}$ \\
\hline 3 & Gear & $5.81 \cdot 10^{-2}$ \\
\hline
\end{tabular}

Table 2: List of constraints in the multi-body model

\begin{tabular}{|l|l|l|l|}
\hline Part I & Part J & Constraint type & No. of constraints \\
\hline Pinion & Ground & Revolute & 5 \\
\hline Gear & Ground & Revolute & 5 \\
\hline
\end{tabular}

Based on the Chebychev-Grüebler-Kutzbach expression, the total number of degrees of freedom for the drive train model can be obtained as follows: 
$n D O F=6($ parts -1$)-\sum$ constraints

This expression yields two degrees of freedom for the devised drive train model, which represent the torsional motions of the pinion and gear. The governing equations of motion are automatically generated by ADAMS in constrained Lagrangian dynamics of the form [19]:

$[J]\left\{\begin{array}{l}\delta q^{j} \\ \delta \gamma_{j}\end{array}\right\}=\left\{F_{a}\right\}$

where, $\left\{q^{j}\right\}=\{x, y, z, \psi, \theta, \phi\}^{T}$ are the generalised Eulerian co-ordinates and $[J]$ is the Jacobian matrix of the form:

$$
[J]=\left[\begin{array}{cc}
{\left[\frac{\partial K}{\partial \dot{q}^{j}}+\frac{\partial U}{\partial q^{j}}\right]} & {\left[\frac{\partial C_{i k}}{\partial \gamma_{j}}\right]} \\
{\left[\frac{\partial C_{i k}}{\partial q^{j}}\right]} & {[0]}
\end{array}\right],
$$

where $j$ refers to co-ordinates $i, k \equiv p$ (pinion), $g$ (gear), $K$ is the kinetic energy and $U$ the potential energy. Thus, the generalised Eulerian resistive forces are: $F_{q^{j}}=-\frac{\partial U}{\partial q^{j}}$, which in the cases of bodies $i, k$ in this example are:

$F_{\psi i}=k_{m} f(l)+c_{m} \dot{\psi}_{i}$

where $i, k \in p, g, k_{m}$ is the dynamic meshing stiffness obtained through tooth contact analysis [6], $c_{m}$ is the structural damping coefficient and:

$f(l)=\left\{\begin{array}{lc}l-b & l \geq b \\ 0 & -b<l<b \\ l+b & l \leq-b\end{array}\right.$

$l$ denotes the spatial line of approach between the meshing teeth pairs ( $l \propto q_{i} \in x, y, z$ ). This is the dynamic transmission error, hence: 
$l=\int_{0}^{t} R_{p} \psi_{p} d t-\int_{0}^{t} R_{g} \psi_{g} d t$

$\gamma_{j}$ are unknown Lagrange multipliers and $C_{i k}$ are constraint functions for joints in the multibody system for the pinion and gear. These are revolute jointed to the ground (rear axle) for parts $i$, resulting in the constraint functions:

$$
\begin{gathered}
x_{i}=0 \\
y_{i}=0 \\
z_{i}=0 \\
\sin \theta_{i} \sin \varphi_{i}=0
\end{gathered}
$$$$
\sin \theta_{i} \cos \varphi_{i}=0
$$

The applied forces $F_{a i}$ are the torques resident on the pinion and the gear, as well as the contribution due to flank friction as:

$$
F_{a i}=T_{i}+T_{f r i}
$$

The resisting torque applied to the wheels is due to traction, which comprises vehicle inertia (motive force), rolling resistance, aerodynamic interaction and grading [20]:

$T_{g}=r_{w} \sum F$

where $r_{w}$ is the laden wheel radius and $\sum F$ is obtained from the vehicle longitudinal dynamics as, the remaining degree of freedom in the analysis:

$\sum F=m a=R_{a}+R_{r l}+R_{g}$

where:

$$
\begin{aligned}
& R_{a}=\frac{\rho}{2} C_{D} A_{f} V^{2} \\
& R_{r l}=f_{r l} W
\end{aligned}
$$

and:

$$
f_{r l}=0.01\left(1+\frac{V}{147}\right)
$$


The demanded instantaneous input torque (on the pinion) is obtained as:

$$
T_{p}=\frac{R_{p}}{R_{g}} T_{g}\left(1+0.1 \cos \left(2 R_{t} A_{p}\right)\right)
$$

The sinusoidal variation as the result of engine order vibration is represented in equation (13) as $10 \%$ oscillations about the nominal engine speed as its second harmonic for the 4-cylinder 4stroke configuration [19], subject of this study. With manoeuvres on nominally flat terrains, the grading contribution is ignored.

The flank friction between pairs of meshing gear teeth contributes to the applied forcing (equation (7)). A thin elastohydrodynamic lubricant film is usually formed in the conjunctions of the meshing teeth pairs of the differential hypoid gears. These thin lubricant films are subject to non-Newtonian viscous shear, supplemented by any asperity interactions (boundary friction as the result of any direct contact of surfaces).

$$
T_{f r i}=R_{i} f_{r}
$$

where the flank friction is obtained as:

$$
f_{r}=f_{v}+f_{b}
$$

The viscous friction is calculated using:

$$
f_{r}=\mu W_{i}
$$

Evans and Johnson [21] presented an analytical-experimental expression for the coefficient of friction, based on the prevailing regime of lubrication. In fully flooded lubricated contacts, friction is due to shear stress of the lubricant film. Based on the prevailing conditions, the shear behaviour of lubricant can reside in one of the following four regimes of lubrication: a) linear viscous or Newtonian, b) non-linear viscous or non-Newtonian, c) visco-elastic and d) elastoplastic. Usually in machine elements the elastic term is negligible [22] and viscous models can define the behaviour of the lubricant. In addition, the Newtonian behaviour can be considered as 
a simplified form of the overall behaviour of lubricant under non-Newtonian shear. Then, the regime b) (i.e. non-Newtonian) can be used for most of the conditions encountered. Equation (17) is obtained by considering this overall behaviour of the lubricant. Then, the shear stress grows with shear rate in a non-linear manner and decreases due to any temperature rise and the ensuing reduction in lubricant viscosity. These effects have been investigated by Crook [23]. Johnson and Greenwood [24] have used the same approach. Equation (17) embodies their approach in order to take into account the thermal effects and pressure dependence of lubricant rheological state under non-Newtonian shear:

$\mu=0.87 \alpha \tau_{0}+1.74 \frac{\tau_{0}}{\bar{p}} \ln \left(\frac{1.2}{\tau_{0} h_{c 0}}\left(\frac{2 \dot{\mathrm{K}} \eta_{0}}{1+9.6 \zeta}\right)^{1 / 2}\right)$

where

$\zeta=\frac{4}{\pi} \frac{\dot{K}}{h_{c 0} / R^{\prime}}\left(\frac{\bar{p}}{E^{\prime} R^{\prime} K^{\prime} \rho^{\prime} c^{\prime} U^{\prime}}\right)^{1 / 2}$

To obtain boundary friction, the Greenwood and Tripp [18] model is used. This model assumes a Gaussian distribution of asperity heights, with a mean radius of curvature for an asperity summit. The area $A_{a}$ of asperity contact and the load carried $P_{a}$ may be estimated as:

$A_{a}=\pi^{2}(\xi \beta \sigma)^{2} A F_{2}(\lambda)$

$P_{a}=\frac{8 \sqrt{2}}{15} \pi(\xi \beta \sigma)^{2} \sqrt{\frac{\sigma}{\beta}} E^{\prime} A F_{5 / 2}(\lambda)$

In these formulae, $A$ is the apparent contact area, $\xi$ is the density of asperity peaks per unit area of contact and $\beta$ is the average summit radius of the curvature of asperities. The statistical functions $F_{2}$ and $F_{5 / 2}$ - given below - are dependent on the Stribeck's oil film parameter $\lambda=h / \sigma$.

$\sigma=\sqrt{\sigma_{1}^{2}+\sigma_{2}^{2}}$

where $\sigma_{1}$ and $\sigma_{2}$ are the average asperity heights of the two contiguous contacting surfaces, respectively. 
The film thickness $h$ is obtained from the extrapolated expression obtained numerically by Chittenden et al [25] for an elliptical point contact with angled lubricant flow entrainment into the conjunction:

$$
h_{c 0}^{*}=4.31 U^{* 0.68} G^{* 49} W^{*^{-0.073}}\left\{1-\exp \left[-1.23\left(\frac{R_{s}}{R_{e}}\right)^{2 / 3}\right]\right\}
$$

where, the non-dimensional groups are:

$\mathrm{W}^{*}=\frac{\pi W_{j}}{2 \mathrm{E}_{\mathrm{r}} \mathrm{R}_{\mathrm{e}}^{2}} \mathrm{U}^{*}=\frac{\pi \eta_{0} \mathrm{u}_{\mathrm{j}}}{4 \mathrm{E}_{\mathrm{r}} \mathrm{R}_{\mathrm{e}}} \mathrm{G}^{*}=\frac{2}{\pi}\left(\mathrm{E}_{\mathrm{r}} \alpha\right)$, and:

$\frac{1}{R_{e}}=\frac{\cos ^{2} \theta}{R_{z x}}+\frac{\sin ^{2} \theta}{R_{z y}}, \frac{1}{R_{s}}=\frac{\sin ^{2} \theta}{R_{z x}}+\frac{\cos ^{2} \theta}{R_{z y}}$

The statistical functions $\mathrm{F}_{2}(\lambda)$ and $\mathrm{F}_{5 / 2}(\lambda)$ are defined as:

$F_{n}(\lambda)=\frac{1}{\sqrt{2 \pi}} \int_{\lambda}^{\infty}(s-\lambda)^{n} e^{s^{2} / 2} d s$

According to Teodorescu et al [26] the results of numerical integration for these functions of interest and their least square fittings yield:

$F_{5 / 2}(\lambda)=-0.1922 \lambda^{3}+0.721 \lambda^{2}-1.0649 \lambda+0.6163$

$F_{2}(\lambda)=-0.116 \lambda^{3}+0.4862 \lambda^{2}-0.7949 \lambda+0.4999$

According to Greenwood and Tripp [18], the roughness parameter $\xi \beta \sigma$ is reasonably constant with a value of $0.03-0.05$ for steel surfaces while the ratio $\sigma / \beta$, which is a measure of average asperity slope is in the range $10^{-4}-10^{-2}$ (this being a representation of the average asperity slope [22]). Assuming $\sigma_{1}=\sigma_{2}$, then: $\xi \beta \sigma=0.040-0.070$ and with an average value of $\xi \beta \sigma=0.055$, the asperity contact area $\mathrm{A}_{\mathrm{a}}$ becomes:

$A_{a}=0.0298 A F_{2}(\lambda)$ 
Considering the same data and assuming $\sigma / \beta=0.001$, the load carried by the asperities becomes: $P_{a}=0.000227 E^{*} A F_{5 / 2}(\lambda)$

The boundary shear is obtained as:

$\tau_{b}=\tau_{L 0}+\lambda^{\prime} P_{a}$

where a thin adsorbed film at the summit of an opposing asperity pair acts in non-Newtonian shear at asperity pressure $p_{a}=\frac{F_{a}}{A_{a}}$. Thus:

$f_{b}=\tau_{b} A_{a}$

It is necessary to calculate the contact load $W_{i}$ for all the simultaneous meshing teeth pairs, which is required for both equations (16) and (22). This is obtained through Tooth Contact Analysis (TCA). The method is outlined in detail by Litvin and Fuentes [14]. Other data for the model are also obtained through TCA, including the instantaneous contact radii of curvature of the pinion and gear teeth surfaces and the variation of contact stiffness during the meshing cycle. At any instant of time in the differential hypoid gears several teeth pairs are in contact in order to carry the high torques generated. TCA calculates the load share per pair of teeth during any meshing cycle, as well as the corresponding meshing stiffness and the static transmission error.

The geometrical, kinematic and load data required for the EHL and efficiency analysis are also obtained from the TCA. The contact load per teeth pair is a function of the dynamic response of the system. However, its distribution among teeth pairs in simultaneous contact is defined quasistatically. A load distribution factor is calculated as a function of the pinion angle for all such contacts. This is the ratio of the applied load $W_{j}$ on a given flank under consideration to the total transmitted load $W_{t}$ (Xu and Kahraman [2]). This is shown in figure 2:

$$
\text { If }=\frac{W_{j}}{W_{t}}
$$

In order to develop the model in ADAMS multi-body environment, two parts representing the pinion and the gear are created. These parts are joined to the ground (representing transmission housing) using revolute joints. Each of these joints introduces 5 constraint functions as described 
in equation (6), thus yielding a 2 degree-of-freedom torsional model. Engine and resisting torques are introduced using equivalent torques on the pinion and the gear respectively. Meshing stiffness and damping forces are presented with instantaneous values of stiffness coefficient and damping ratios. These instantaneous values are imported in the form of Fourier Functions. These functions are produced from quasi-static calculations from Tooth Contact Analysis (TCA). The calculations have been performed for different applied torques and the resulting functions are based on the pinion angle.

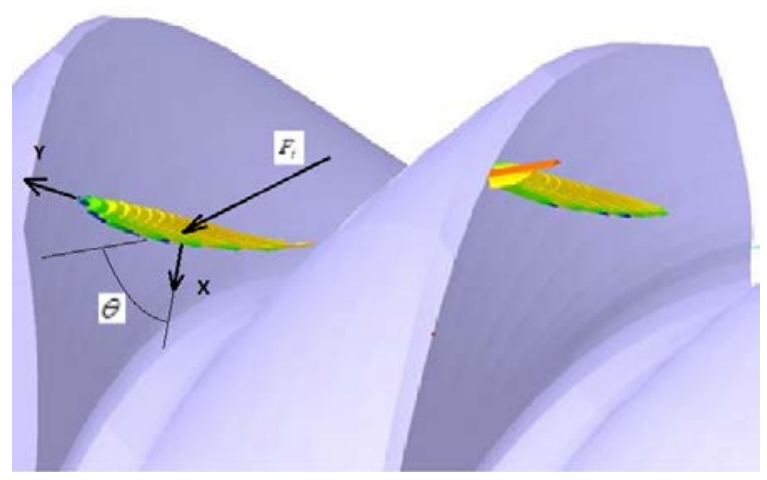

Figure 2: Flank load on subsequent teeth

The specifications for the face-hobbed, lapped hypoid gear pair in this study are listed in table 3.

Table 3a: Pinion parameters

\begin{tabular}{|c|c|}
\hline Parameter name & Pinion \\
\hline number of teeth & 13 \\
\hline face-width (mm) & 33.851 \\
\hline face angle (deg) & 29.056 \\
\hline pitch angle (deg) & 29.056 \\
\hline root angle (deg) & 29.056 \\
\hline spiral angle (deg) & 45.989 \\
\hline pitch apex (mm) & -9.085 \\
\hline face apex (mm) & 1.368 \\
\hline outer cone distance (mm) & 83.084 \\
\hline sense (Hand) & Right \\
\hline
\end{tabular}


Table 3b: Gear parameters

\begin{tabular}{|c|c|}
\hline Parameter name & Gear \\
\hline number of teeth & 36 \\
\hline face-width (mm) & 29.999 \\
\hline face angle (deg) & 59.653 \\
\hline pitch angle (deg) & 59.653 \\
\hline root angle (deg) & 59.653 \\
\hline spiral angle (deg) & 27.601 \\
\hline pitch apex (mm) & 8.987 \\
\hline face apex (mm) & 10.948 \\
\hline outer cone distance (mm) & 95.598 \\
\hline offset (mm) & 24 \\
\hline sense (Hand) & Left \\
\hline
\end{tabular}

\section{Results and Discussion}

Transmission efficiency (thus reduced parasitic losses) and NVH refinement are the key concerns in the design of gearing systems [8]. The current analysis investigates these performance measures for a pair of hypoid gears of a light van differential. The related input parameters for the analysis are presented in tables 4 and 5. Most of the critical phenomena in relation to efficiency and $\mathrm{NVH}$ usually take place during transient response (in acceleration and/or deceleration). Firstly, a manoeuvre as a section of typical take-off from a city driving mode in line with the NEDC is considered (figure 3). The accelerated manoeuvre is assumed from $5 \mathrm{mph}$ to about $60 \mathrm{mph}$. In fact, this manoeuvre culminates in highway driving conditions. In order to have realistic applied torques on the pinion, during acceleration, transmission gear shifts are assumed between $2^{\text {nd }}$ and $3^{\text {rd }}$ gears at $3500 \mathrm{rpm}$ and between $3^{\text {rd }}$ and $4^{\text {th }}$ gears at $3200 \mathrm{rpm}$. Then, acceleration continues up to $3000 \mathrm{rpm}$ engine speed. The calculated speed of vehicle during this process is presented in figure 4 . For all calculations, $60 \%$ wide open throttle torque is assumed. 
Table 4: Input operating conditions

\begin{tabular}{|l|l|}
\hline Parameter & Value \\
\hline$A_{f}$ (frontal area) & $2.2 \mathrm{~m}^{2}$ \\
\hline$f_{r l}$ (coefficient of rolling resistance) & 0.0166 \\
\hline$C_{D}$ (drag coefficient) & 0.33 \\
\hline$\rho$ (air density) & $1.22 \mathrm{~kg} / \mathrm{m}^{3}$ \\
\hline W (vehicle weight) & $1300 \mathrm{~kg}$ \\
\hline Tyre (type) & $\mathrm{P} 205 / 65 \mathrm{R} 15 \mathrm{BSW}$ \\
\hline $2^{\text {nd }}$ gear ratio & $2.038: 1$ \\
\hline $3^{\text {rd }}$ gear ratio & $1.281: 1$ \\
\hline $4^{\text {th }}$ gear ratio & $0.951: 1$ \\
\hline Surface Roughness of solids & $0.5 \mu \mathrm{m}$ \\
\hline
\end{tabular}

Table 5: Physical properties of the lubricant and solids

\begin{tabular}{|l|l|}
\hline Pressure viscosity coefficient $(\alpha)$ & $2.383 \times 10^{-8}\left[\mathrm{~Pa}^{-1}\right]$ \\
\hline Lubricant atmospheric dynamic viscosity at $40^{\circ} \mathrm{C}\left(\eta_{0}\right)$ & $0.195[\mathrm{~Pa} . s]$ \\
\hline Atmospheric dynamic viscosity @ $100^{\circ} \mathrm{C}\left(\eta_{0}\right)$ & $0.0171[\mathrm{~Pa} . \mathrm{s}]$ \\
\hline Lubricant Eyring shear stress $\tau_{0}$ & $2[\mathrm{MPa}]$ \\
\hline$\tau_{L 0}$ & $2.3[\mathrm{MPa}]$ \\
\hline Pressure-induced shear coefficient $\left(\lambda^{\prime}\right)$ & 0.08 \\
\hline Heat capacity of fluid & $0.14\left[\mathrm{~J} / \mathrm{kg}^{\circ} \mathrm{K}\right]$ \\
\hline Thermal conductivity of fluid & $2000\left[\mathrm{~W} / \mathrm{m}^{\circ} \mathrm{K}\right]$ \\
\hline Modulus of elasticity of contacting solids & $210[\mathrm{GPa}]$ \\
\hline Poisson's ratio of contacting solids & $0.3[-]$ \\
\hline Density of contacting solids & $7850\left[\mathrm{~kg} / \mathrm{m}^{3}\right]$ \\
\hline Thermal conductivity of contacting solids & $46\left[\mathrm{~W} / \mathrm{m}^{\circ} \mathrm{K}\right]$ \\
\hline Heat capacity of contacting solids & $470\left[\mathrm{~J} / \mathrm{kg}^{\circ} \mathrm{K}\right]$ \\
\hline
\end{tabular}

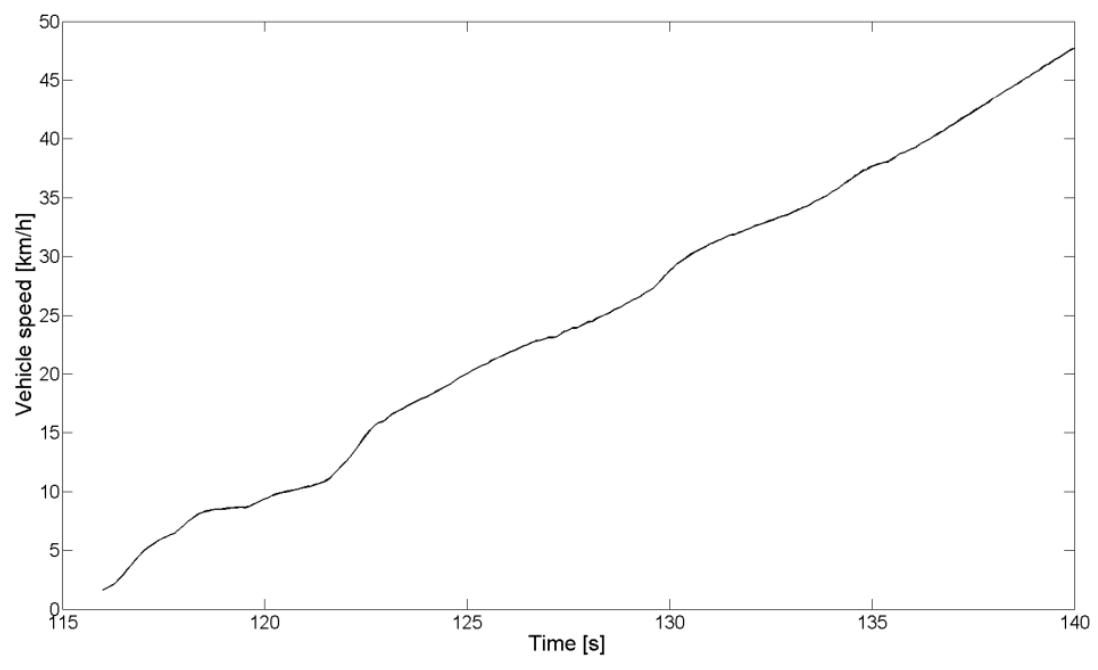

Figure 3: A typical part of the NEDC 


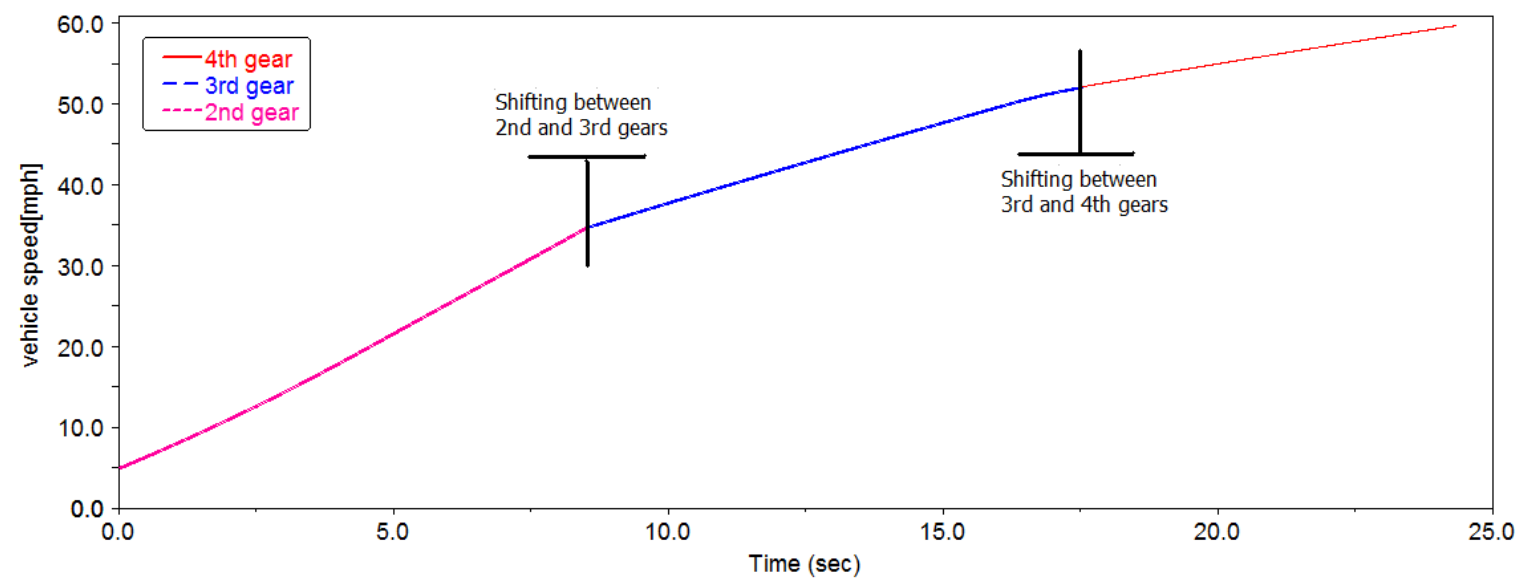

Figure 4: Vehicle speed from NEDC condition to highway driving

The calculated applied torque, $T_{p}$ (equation (13)) on the pinion is shown in figure 5(a). This is the torque variation for the engine map (figure 5(b)) for the gear shifts corresponding to the conditions in figure 4.

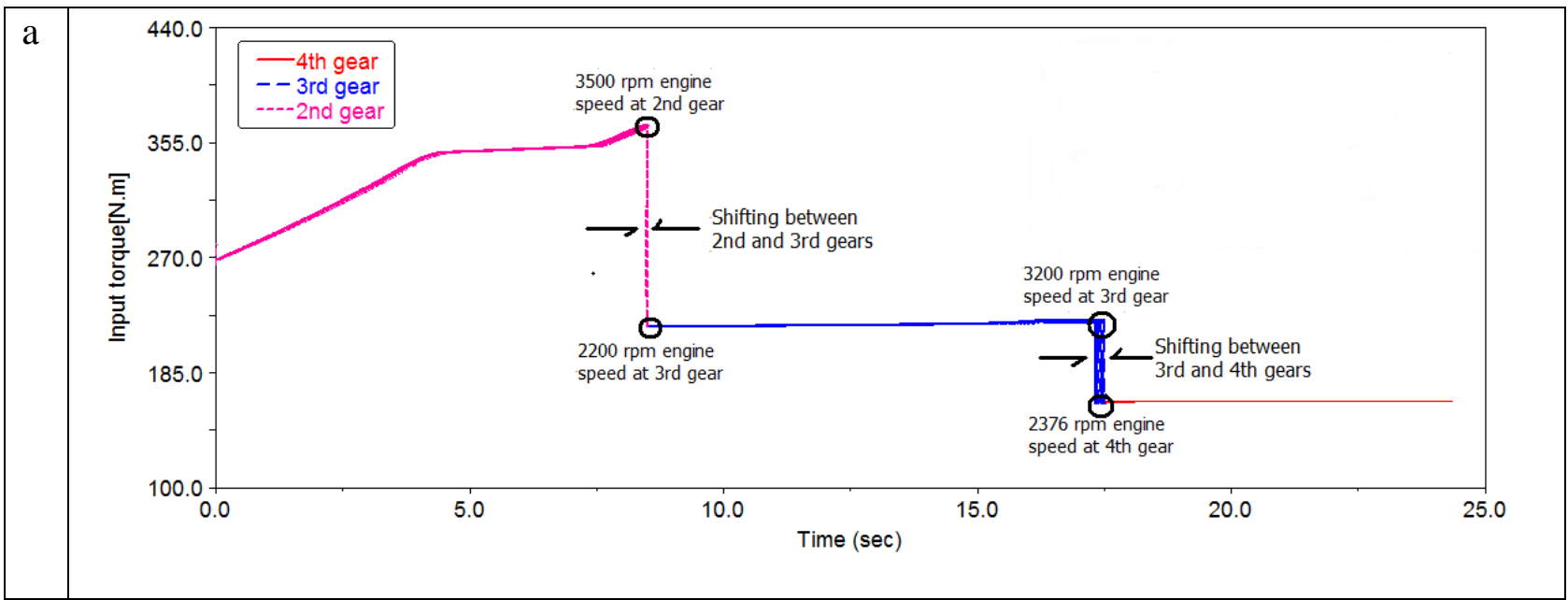




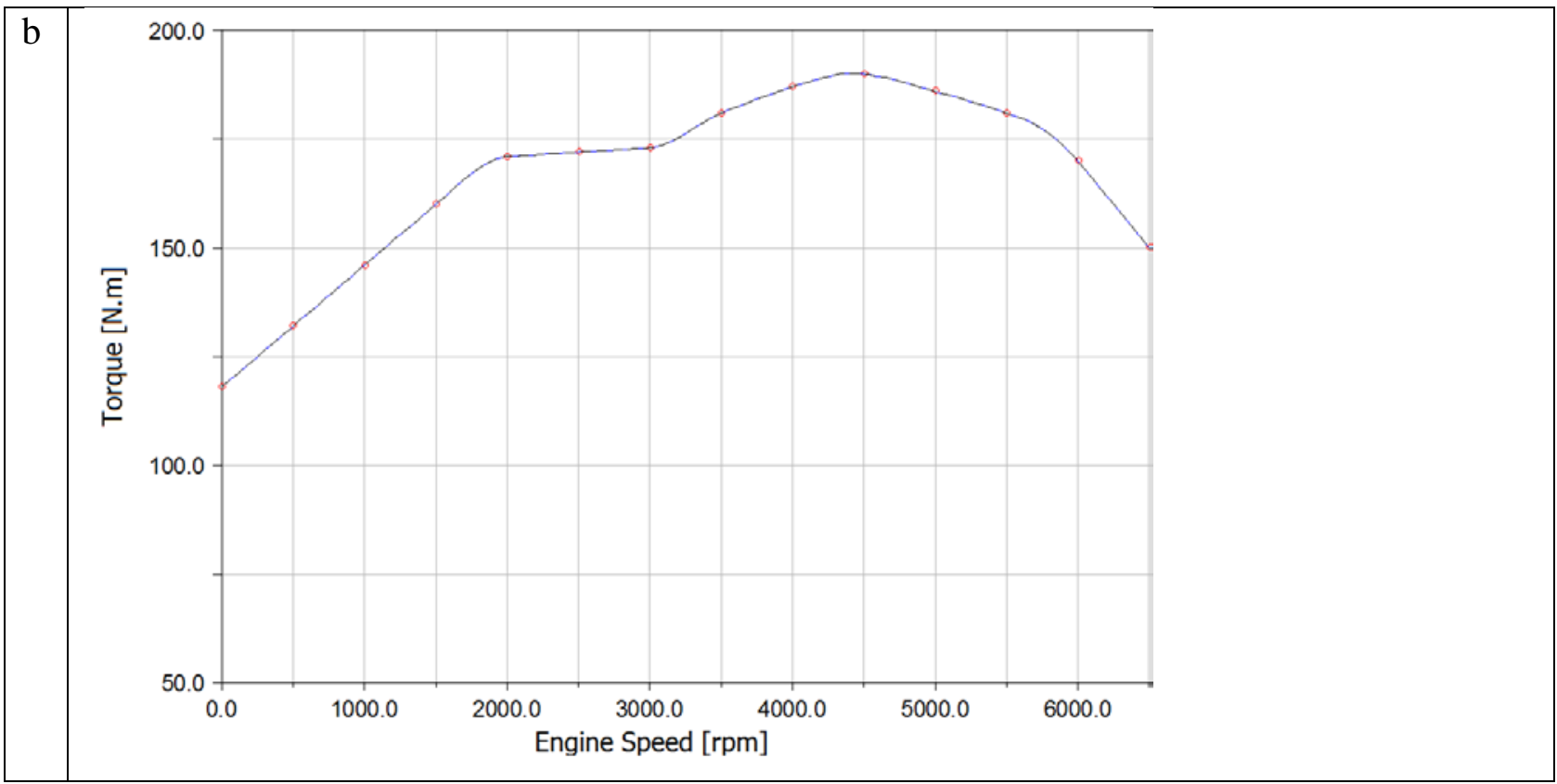

Figure 5: (a) Applied pinion torque during the manoeuvre of figure 4, (b) The vehicle engine map

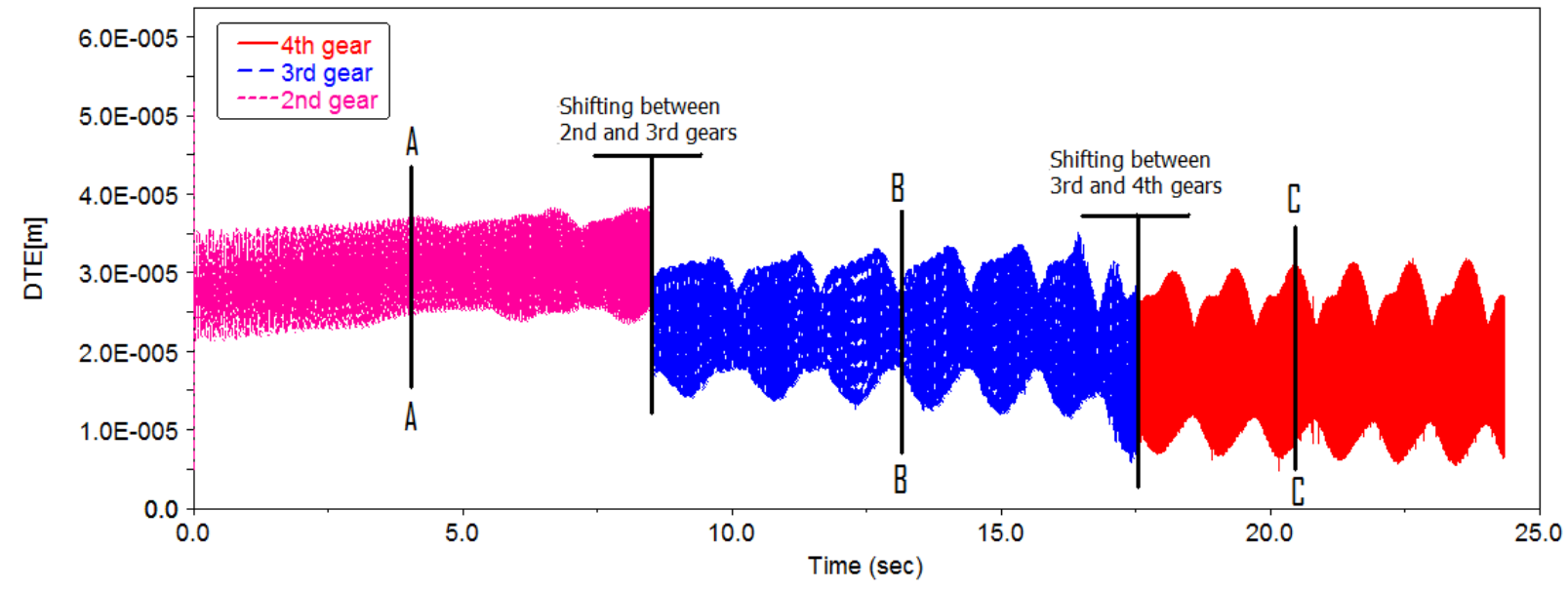

Figure 6: DTE during acceleration

The predicted dynamic transmission error (DTE) during the specified manoeuvre is shown in figure 6. There are 3 distinct regions in the DTE characteristic response shown in the figure. These comprise a transient part of the NEDC, marked by the typical instantaneous A-A response, the eventual highway driving condition C-C and the transition period, regarded as an off-NEDC manoeuvre, represented by the instantaneous response B-B. Figures 7(a)-(c) show the localised 
time histories in the above regions (A-A, B-B and C-C) with their corresponding wavelet plots. Two spectral contributions dominate the signal in all cases. One is the meshing frequency, $\mathrm{f}_{\mathrm{m}}$, and the other is the forcing frequency (second engine order torsional vibration, resident on the transmission output shaft of the simulated 4-stroke, 4-cylinder engine), $\mathrm{f}_{e}=\frac{1}{2 \pi}\left(2 R_{t} A_{p}\right)$ (see equation (13)). Also, note the small modulation effects between these frequencies, $f_{m}-f_{e}$ and $f_{m}+f_{e}$ as well as harmonics of the meshing frequency. All spectral contributions are subject to a gradually increasing frequency value owing to the accelerative nature of the manoeuvre (curvilinear characteristic loci). Of note is the intermittency in the nature of response amplitude at the meshing frequency (repetitive regions of rise and fall in amplitude in the characteristic locus of the meshing frequency), particularly at the higher vehicle speeds. Figure 8 shows two spectra of vibration at close instances during meshing (market by lines a-a and b-b in figure 7(c)). Physical interpretation of this is amplitude perturbation at the meshing frequency because of changes in lubricated contact dynamics (slide-roll speed ratio and lubricant reaction through mesh). This oscillatory behaviour is known to cause pressure perturbations which can emanate as noise. This phenomenon is quite similar to transmission drive rattle condition (with partial loading) [8], which causes teeth pair oscillations within the confine of their backlash. For axle whine condition, Koronias et al [10] noted that diminished amplitude contribution at the meshing frequency or conversely an increased contribution at the forcing frequency (engine order vibration) results in the axle whine phenomenon. The results here conform to their findings. 

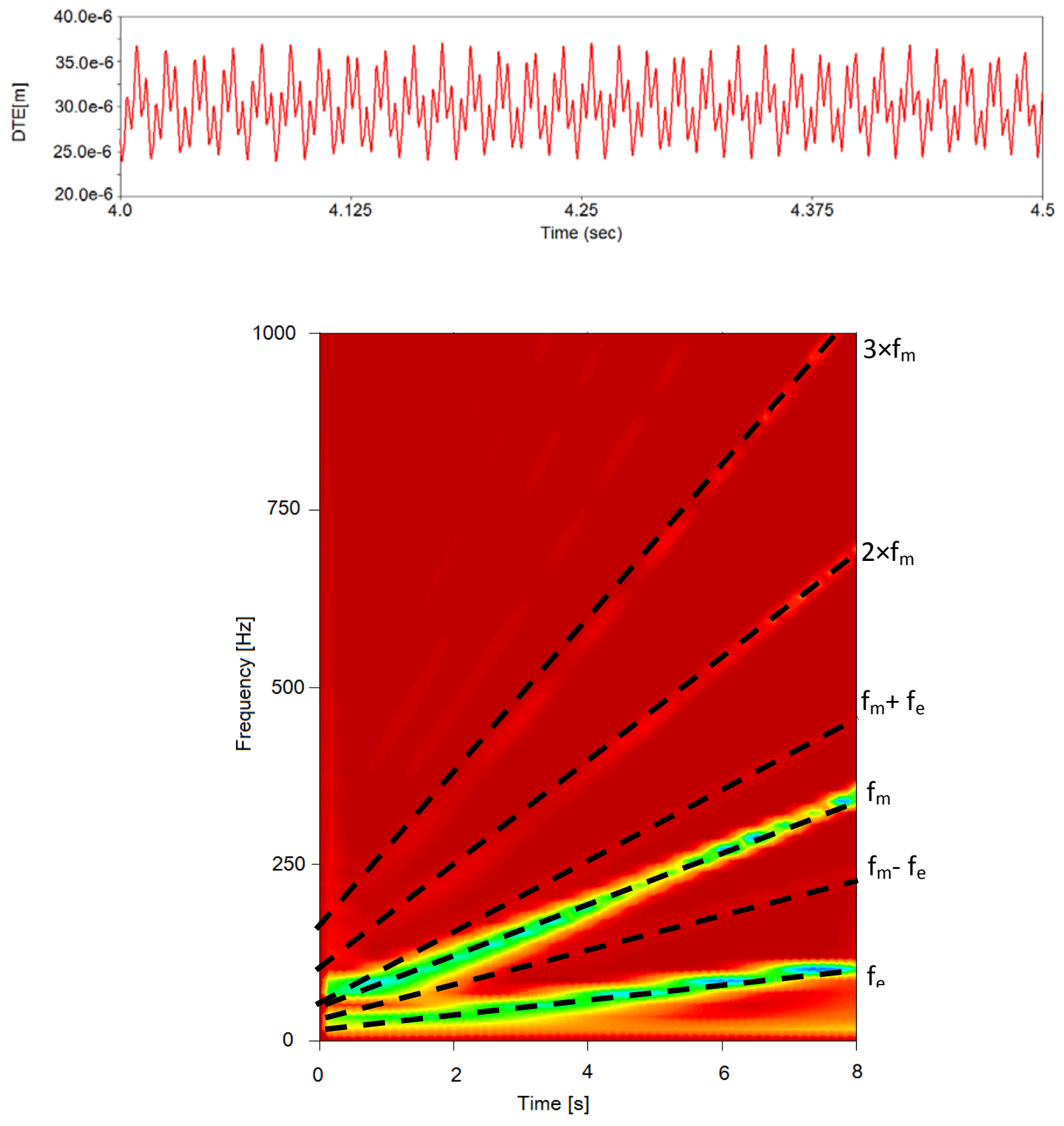

(a)- Wavelet of response for second gear (transient NEDC) and time history of section A-A 

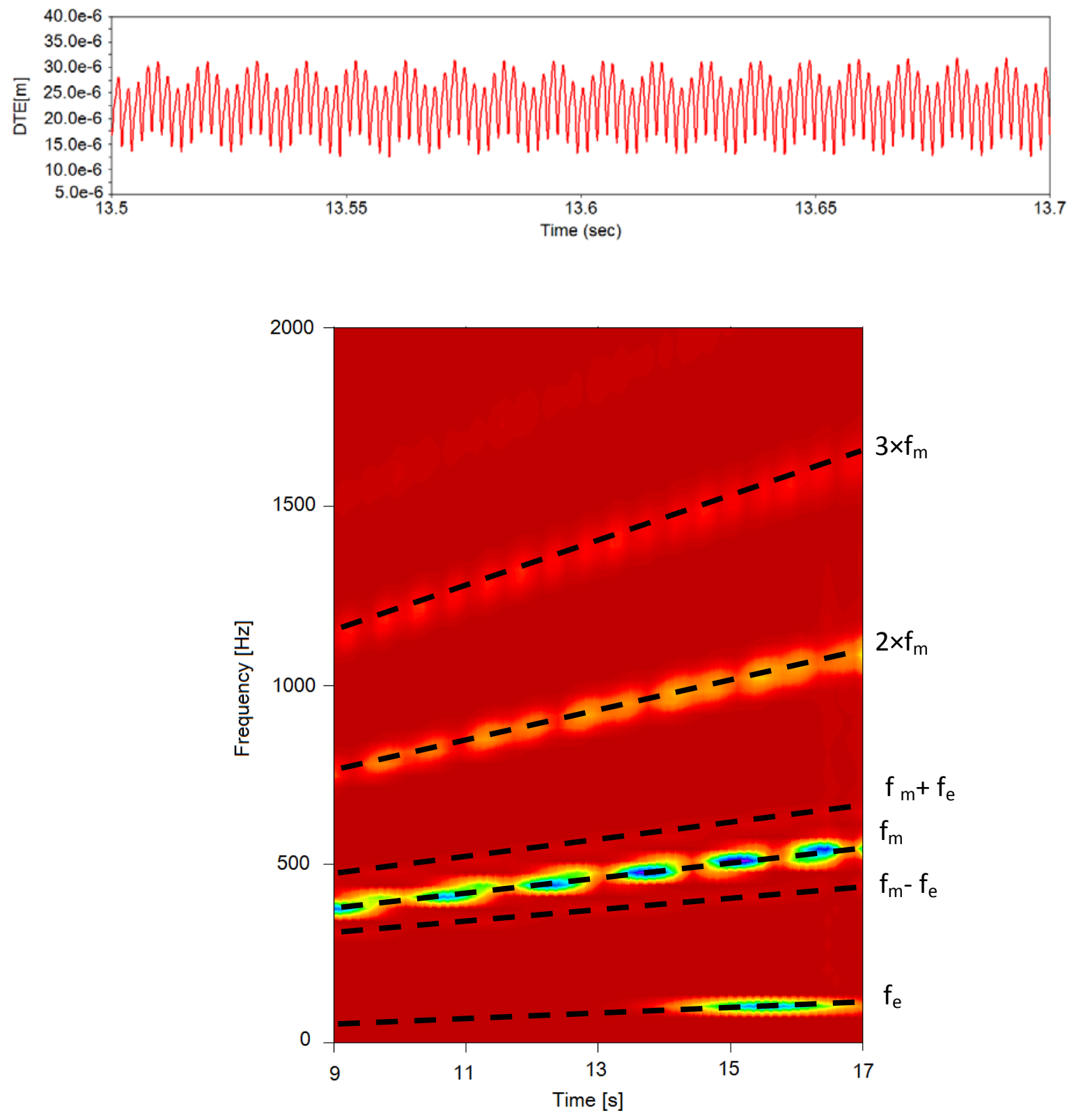

(b)- Wavelet of response for third gear (transition to highway driving) and time history of section B-B 

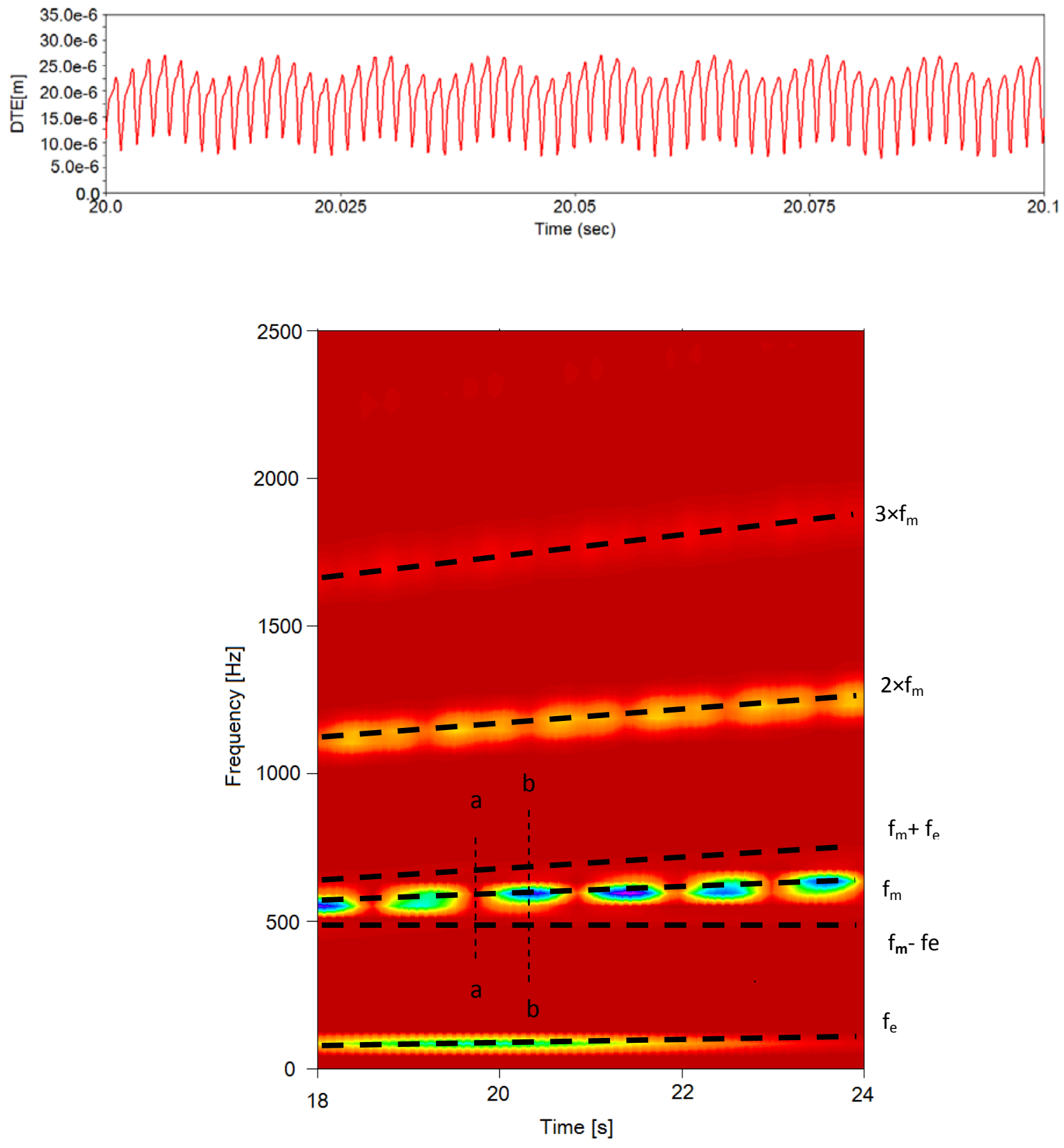

(c)- Wavelet of response for fourth gear (highway driving) and time history of section C-C Figure 7: DTE and its spectral content from city to highway driving conditions 


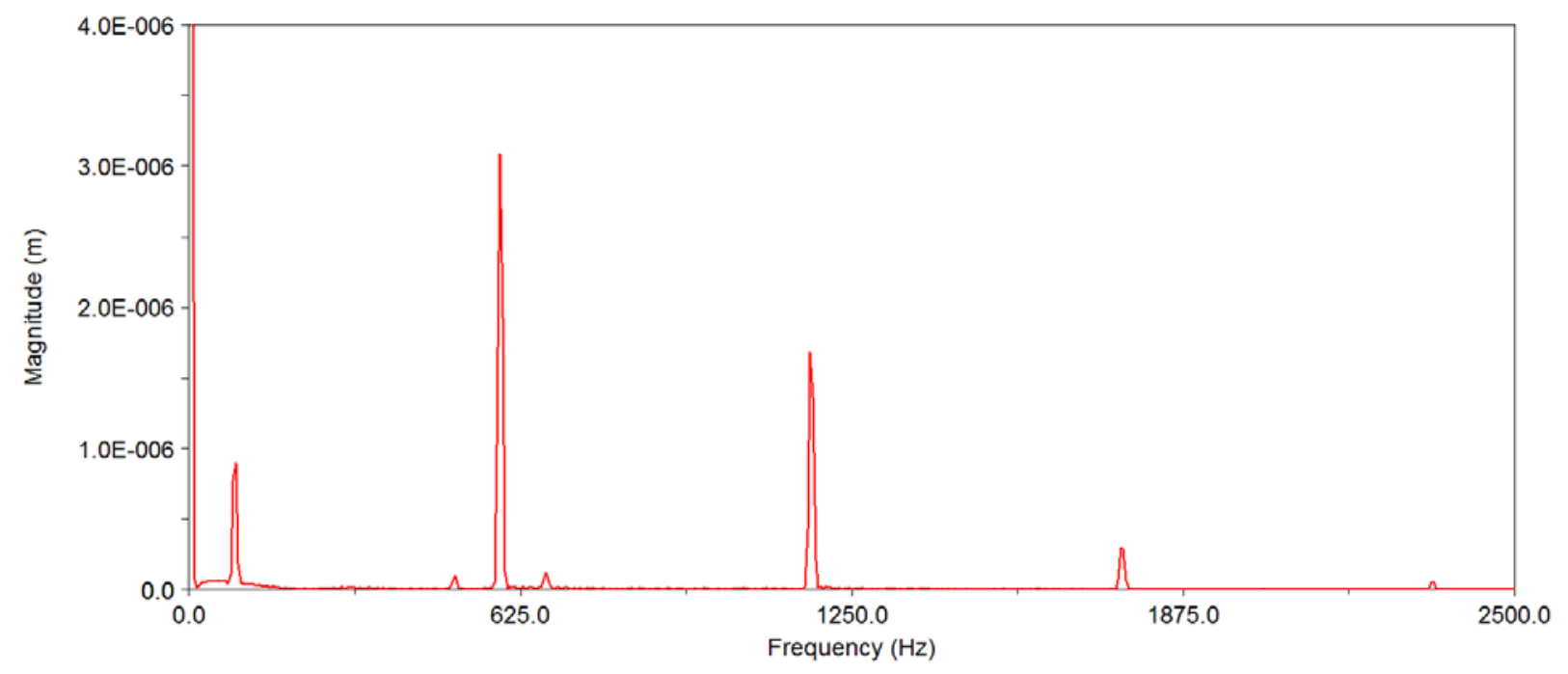

(a)- the instantaneous response corresponding the line (b-b) in figure 7(c)

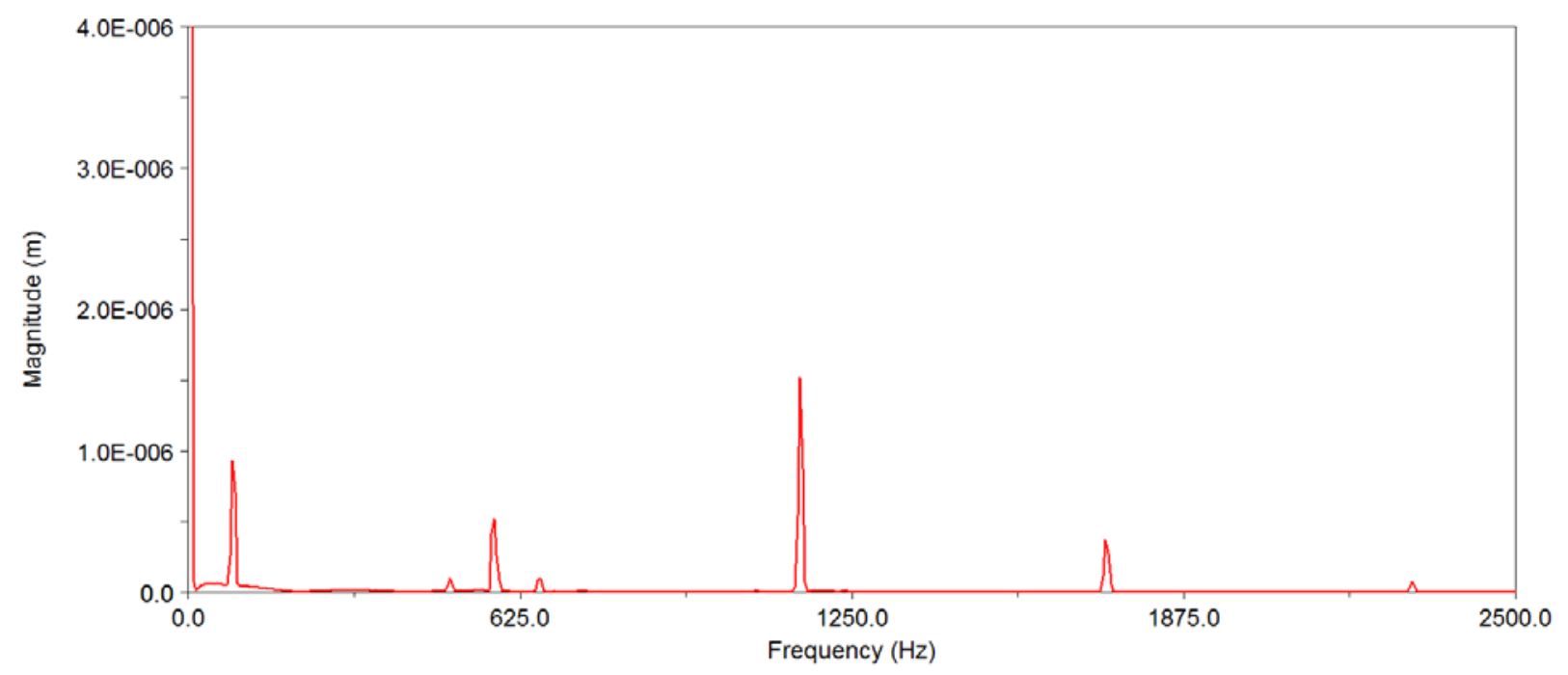

(b)- the instantaneous response corresponding the line (a-a) in figure 7(c)

Figure 8: Instantaneous spectral responses corresponding to highlighted region in figure 7(c)

To obtain flank friction it is important to calculate the lubricant film thickness in the conjunctions of mating meshing gear teeth pairs. At any instant of time three pairs of teeth are in simultaneous mesh. The load share per teeth pair, $W_{j}$, is obtained from equation (30) and used together with the instantaneous contact kinematics, $u_{j}$ (obtained through TCA) and the lubricant rheological parameters (listed in table 5) in equation (22) to obtain the instantaneous teeth pair lubricant film thickness. This is shown in figure 9, where the three teeth pairs in simultaneous contact are 
denoted by the leading, middle and trailing contacting teeth pairs. Note the thin film thickness of the order of $0.1-0.15 \mu \mathrm{m}$, which results in oil film parameter ratio $\lambda<3$, indicating a mixed regime of lubrication where a percentage area of contact experiences direct surface interactions (boundary friction). Furthermore, such thin films at relatively high shear promote non-Newtonian viscous shear, which is the reason for employing equations (17) and (18).

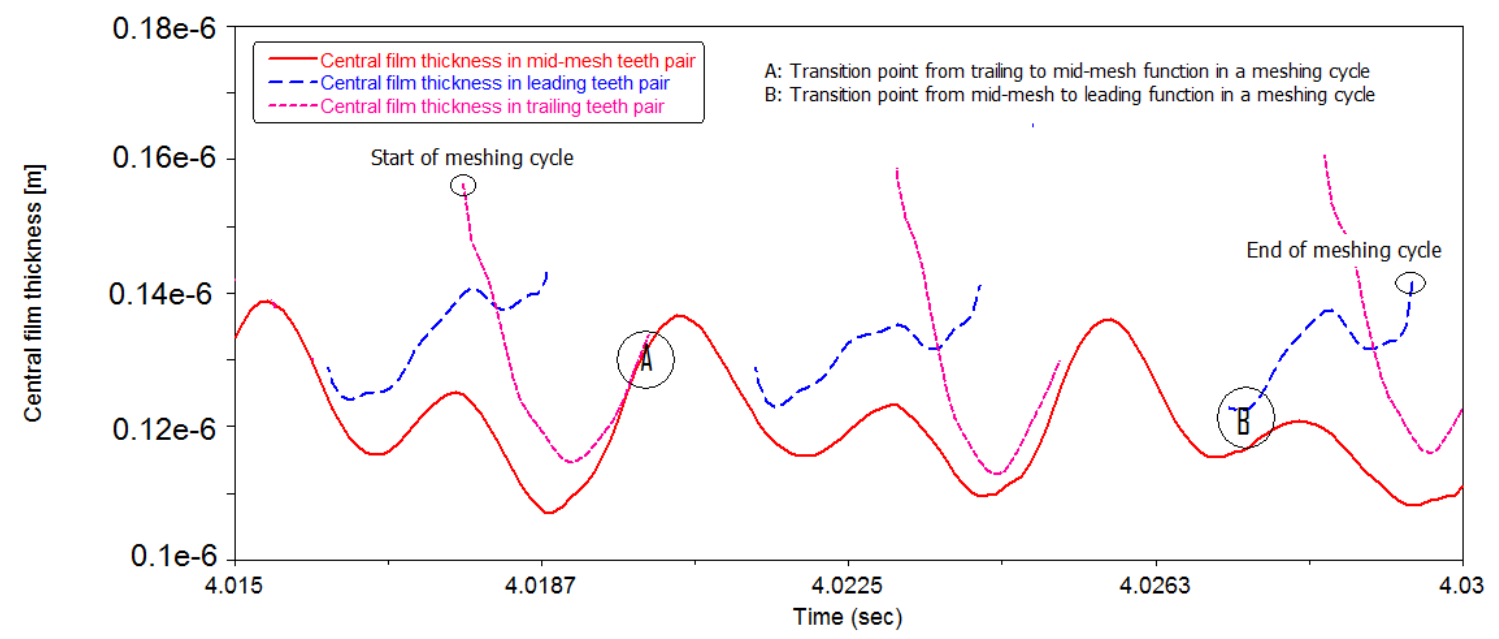

Figure 8: Lubricant film thickness variation for teeth pair contacts at the lubricant bulk oil temperature of $100^{\circ} \mathrm{C}$

The friction per contacting meshing teeth pairs is obtained, using equations (15), (16) and (29). Figure 10 shows the flank friction for the same conditions as those in figure 7. With an assumed fully flooded lubrication condition, a thicker film is formed in teeth-pair conjunctions through mesh. This decreases the viscous shear stress, as well as reducing the contribution due to any boundary interactions. Thus, friction reduces at higher speeds as the lubricated conjunction is subjected to elastohydrodynamic regime of lubrication and the lubricant film thickness is insensitive to load [22]. Conditions which correspond to reduced friction promote increased residual vibratory energy. Figures 10(a)-(c) show decreased average friction with increased vehicle speed, a trend which is inversely related to figures 7(a)-(c). Thus, differential efficiency and NVH refinement are contradictory desired attributes. The defined NEDC cycle is motivated by fuel efficiency and reduced emissions, thus it is based upon low driving speeds, where frictional losses are more pronounced, without regard to NVH refinement. However, various 
$\mathrm{NVH}$ phenomena have progressively become key vehicle customer concerns, as well as potential sources of warranty claims [10,12].

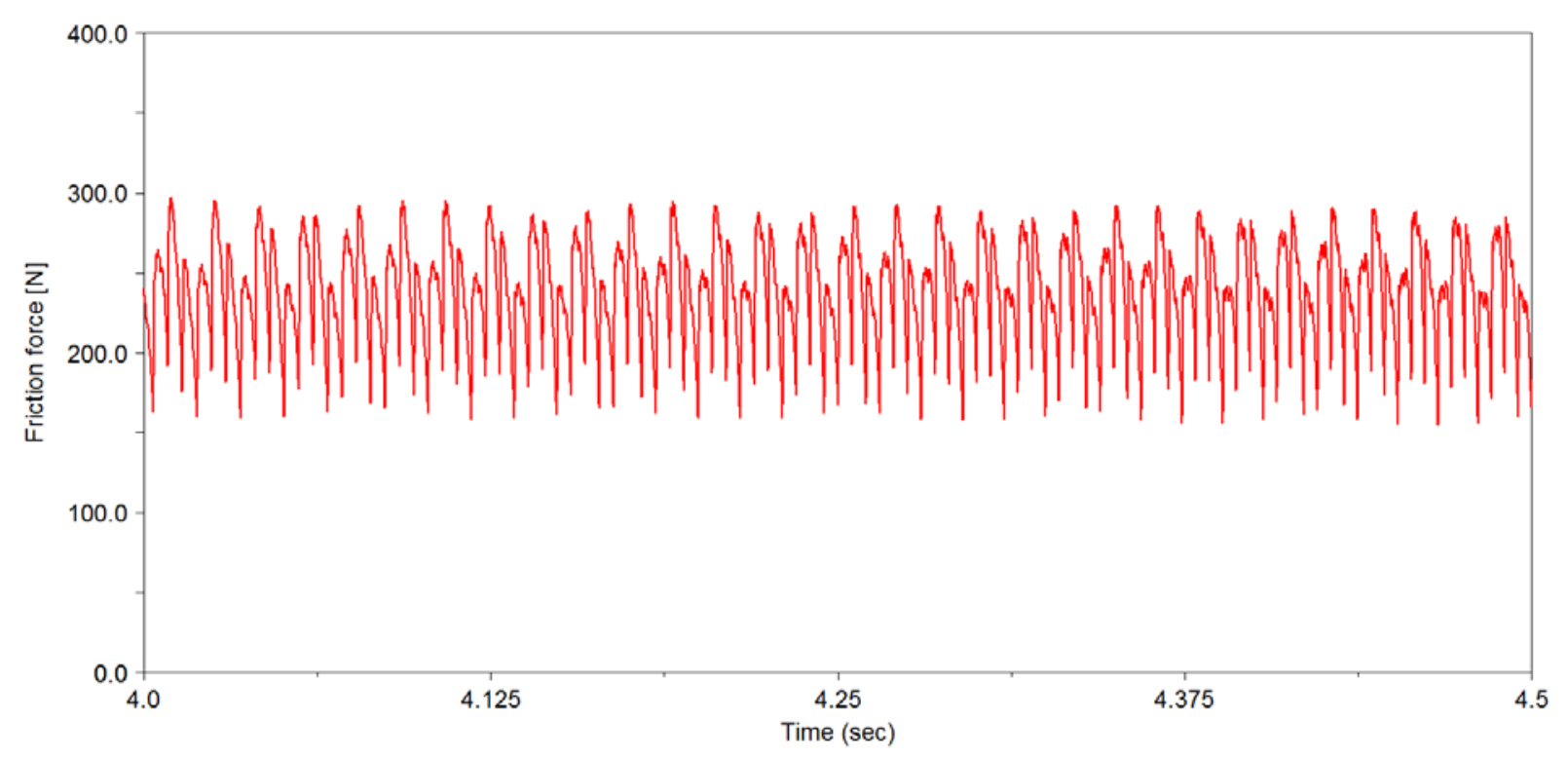

(a)- Calculated friction in section A-A (transient NEDC)

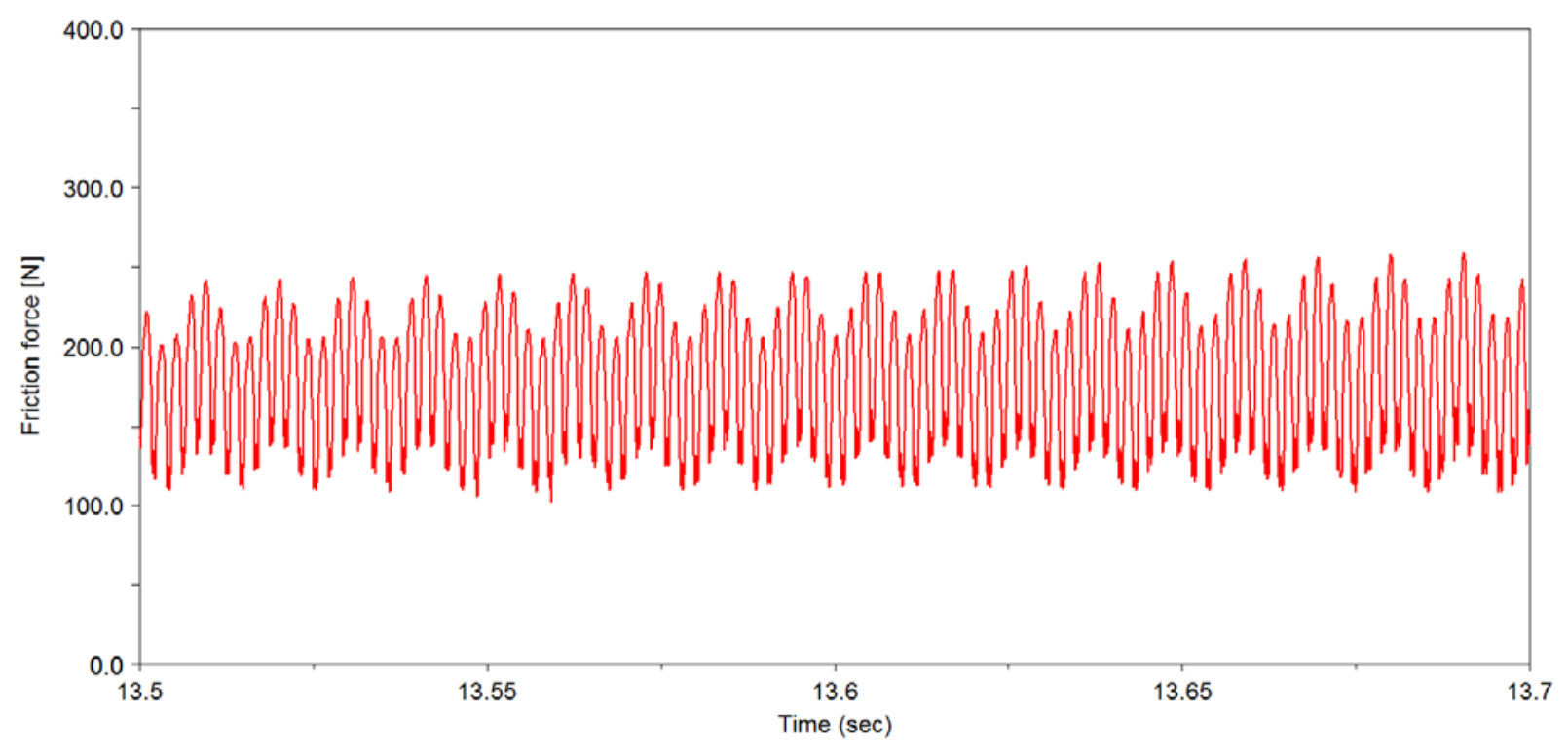

(b)- Calculated friction in section B-B (transition to highway driving) 


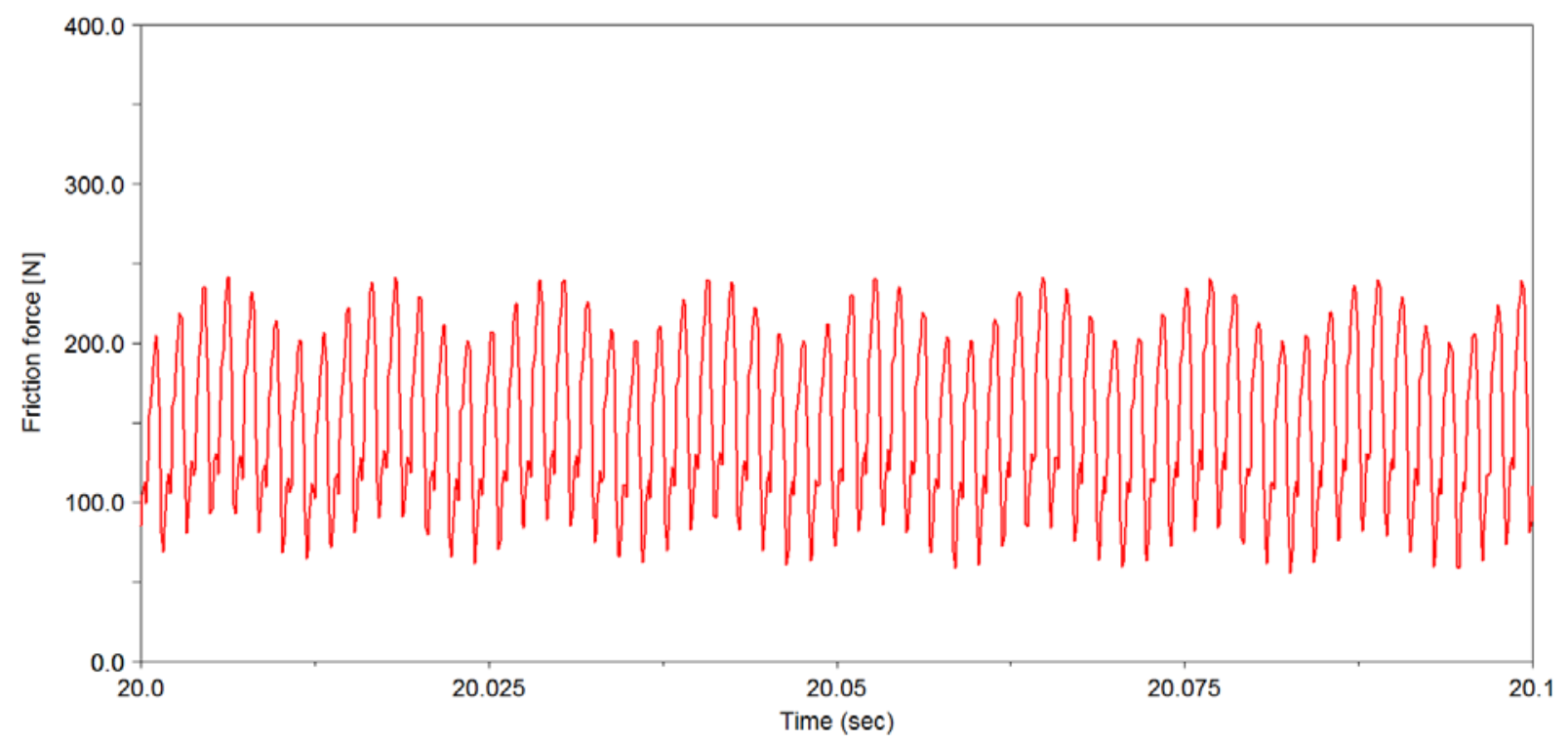

(c)- Calculated friction in section C-C (highway driving)

Figure 10: Calculated friction from city to highway driving conditions

The trend of improved transmission efficiency with increased vehicle speed is further depicted in figure 11, which corresponds to the driving manoeuvre presented in figure 5 . The transmission inefficiency is defined as: $\varepsilon=\frac{\sum_{j} P_{f j}}{T \omega} \times 100$, where $P_{f j}=f_{r j} \Delta u_{j}$ is the frictional power loss, $\Delta u_{j}$ is the sliding velocity of teeth pairs $j, T$ and $\omega$ are pinion torque and angular velocity, respectively. Figure 11 shows that the transmission inefficiency due to differential hypoid gear pair at higher engine speeds, accounts for a mere $1-2 \%$ of all the power train losses, which is nevertheless quite significant. At low speeds, representative of the transient accelerative part of the NEDC cycle, the transmission inefficiency can be significantly higher, as shown in the figure. These predictions are in line with findings of other researchers. For hypoid gears, there have been scoring tests and efficiency measurements by Naruse et al [27] and approximation of power loss for hypoid gears as a combination of spiral bevel gears and a worm gear by Buckingham [28]. These studies have indicated transmission inefficiency in the order of $2-4 \%$. A more comprehensive analysis is carried out by Xu et al [29], who used a combination of TCA and thermo-elastohydrodynamics of hypoid gear pairs to predict the coefficient of friction. For an assumed lubricant Newtonian behaviour, the transmission mechanical inefficiency was predicted to be in the range 2-3\%. Recently an experimental investigation of axle efficiency has been presented by Hurley [30], indicating an overall efficiency of $2-8 \%$ for a range of speeds and torques. 


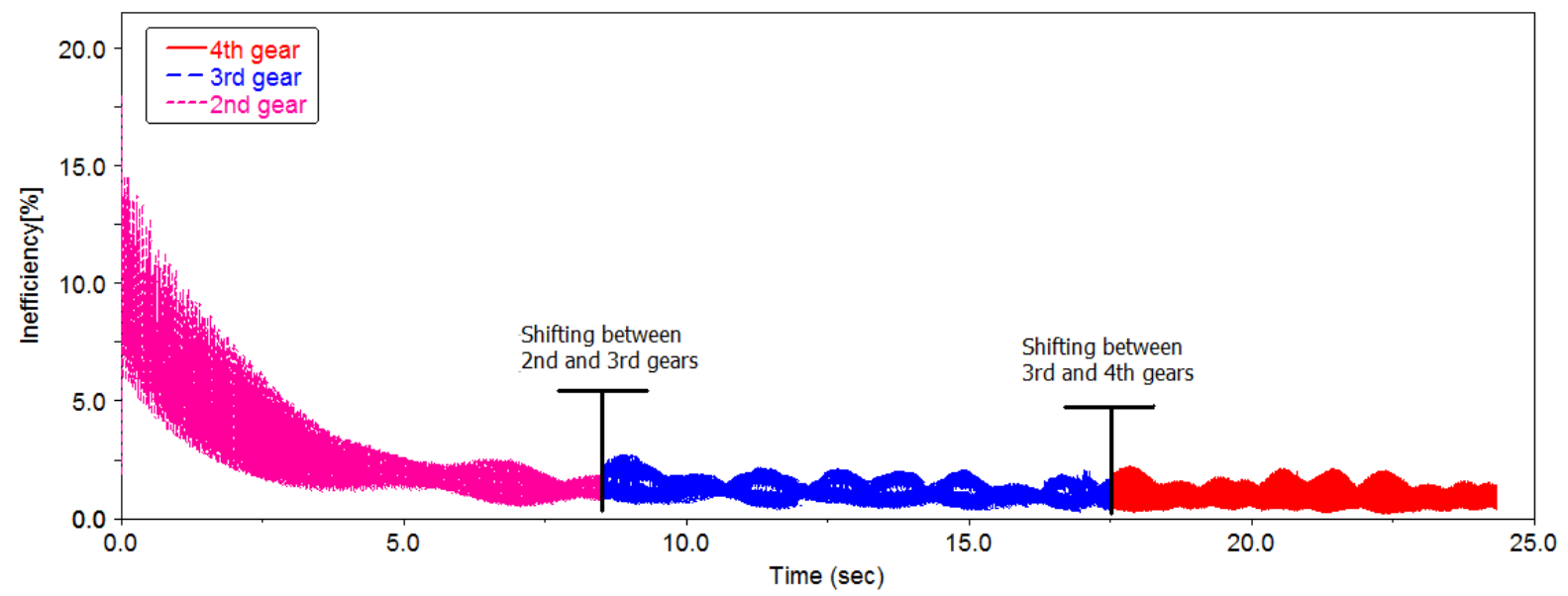

Figure 10: Transmission inefficiency during acceleration

\section{Conclusions}

The results of the analyses indicate that transient tests such as those described in this paper are more representative when studying combined transmission efficiency and NVH refinement, rather than the NEDC, which is heavily focussed only on the assessment of fuel efficiency and resulting emissions. The link between NVH refinement and transmission efficiency has been investigated. It is shown that NVH performance deteriorates during transient accelerative motion, which at high speeds improves the chance of lubricant film formation and decreases transmission inefficiency. The converse is true at low speed steady state driving conditions which form the main part of the NEDC.

In conclusion, compliance with directives set through NEDC is just one trend in the future developments, the other is $\mathrm{NVH}$ refinement, which is progressively viewed as a measure of quality.

\section{Acknowledgements}

The authors would like to express their gratitude to Ford Motor Company for support of this research project and the Advanced Numerical Solutions Inc. for access to the TCA tool CALYX.

\section{Nomenclature}

$\underline{\text { A } \quad \text { : Apparent contact area }}$ 


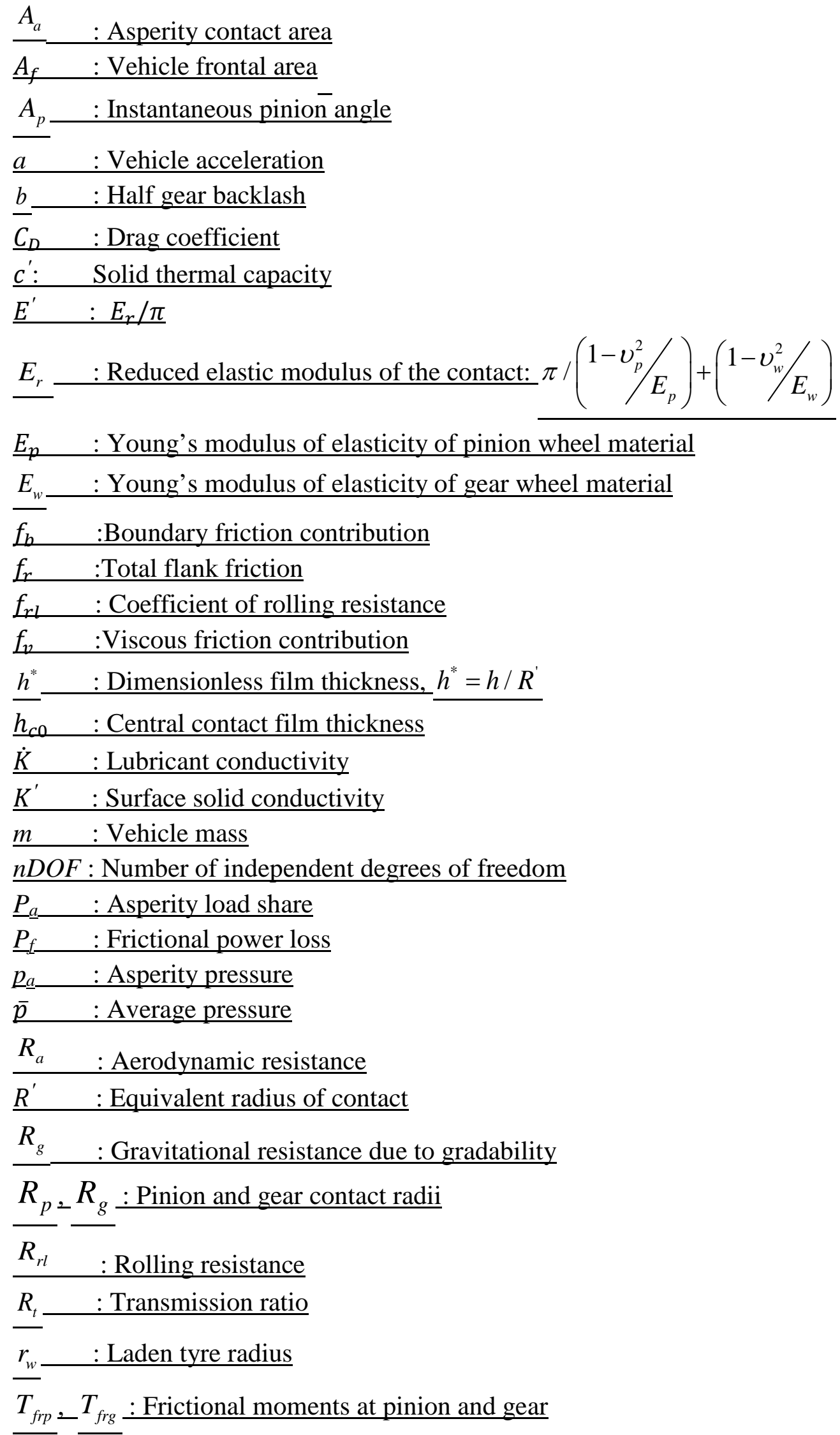


$T_{p 2} T_{g}$ : Externally applied torques to the pinion and gear

$\underline{t}$ : Time

$u_{j} \quad$ : Instantaneous speed of lubricant entraining motion per teeth pair

$\Delta u \quad$ : Contact sliding velocity

$V \quad$ : Vehicle speed [mph]

$\underline{W} \quad$ : Vehicle weight

$W_{j} \quad$ : Contact load per meshing teeth pair

\section{Greek symbols:}

$\alpha \quad$ : Lubricant pressure-viscosity coefficient

$\eta_{0} \ldots$ : Lubricant dynamic viscosity at atmospheric pressure

$\underline{\theta} \quad$ : Angle of lubricant entrainment into the contact

$\lambda \quad$ : Stribeck's oil film parameter

$\underline{\lambda^{\prime}} \quad$ :Pressure-induced shear coefficient

$\mu \quad$ : Coefficient of friction

$v_{w} \quad$ : Poisson's ratio of the gear wheel material

$v_{p} \ldots$ : Poisson's ratio of the pinion gear material

$\rho \quad$ : Density of air

$\rho^{\prime} \quad$ : Solid surface density

$\underline{\sigma} \quad$ : Average surface roughness of contacting surfaces

$\tau_{0} \ldots$ : Eyring shear stress

$\tau_{L 0} \quad$ : Limiting shear stress

$\underline{\omega} \quad$ : Instantaneous angular velocity of the pinion

\section{Subscripts:}

$\underline{b} \quad$ : Denotes boundary contribution

$g \quad$ : Denotes the gear wheel

$j \quad$ : Refers to a teeth pair in mesh

$p \quad$ : Denotes the pinion

$\underline{v} \quad$ : Refers to viscous shear

\section{References:}

[1] Kolivand, M. and Kahraman, A. "A load distribution model for hypoid gears using ease-off topography and shell theory”, Mechanism \& Machine Theory, 2009, 44, pp. 1848-1865 
[2] Xu, H. and Kahraman, A. "Prediction of friction-related power losses of hypoid gear pairs”, Proc. Instn. Mech. Engrs, J. Multi-body Dyn., 2007, 221, pp. 387-400

[3] Cheng, Y. and Lim, T.C., "Vibration analysis of hypoid transmission applying an exact geometry based gear mesh theory”, Journal of Sound and Vibration, 2001, 240(3), pp. 519-543

[4] Cheng, Y and Lim, T.C., "Dynamics of hypoid gear transmission with non-linear timevarying mesh characteristics”, Trans. ASME, Journal of Mechanical Design 2003, 125, pp.373382.

[5] Wang, J., Lim, T.C. and Li, M., "Dynamics of a hypoid gear pair considering the effects of time-varying mesh parameters and backlash nonlinearity”, Journal of Sound and Vibration, 2007, 229(2), pp.287-310.

[6] Karagiannis, Y., Theodossiades, S. and Rahnejat, H. “On the dynamics of lubricated hypoid gears”, Mechanism \& and Machine Theory, 2012, 48, pp. 94-120

[7] Mohammadpour, M., Theodossiades, S. and Rahnejat, H. "Elastohydrodynamic lubrication of hypoid gears at high loads”, Proc. Instn. Mech. Engrs., Part J: J. Engng. Tribology, 2012, 226

(3), pp. 183-198

[8] De la Cruz, M., Theodossiades, S. and Rahnejat, H. “An investigation of manual transmission drive rattle”, Proc. Instn. Mech. Engrs, Part K: J. Multi-body Dyn., 2010, 224(2), pp. 167-181.

[9] Tangasawi, O., Theodossiades, S. and Rahnejat, H. "Lightly loaded lubricated impacts: idle gear rattle”, J. Sound \& Vibration, 2007, 308(3-5), pp. 418-430.

[10] Koronias, G., Theodossiades, S., Rahnejat, H. and Saunders, T. “Axle whine phenomenon in light trucks: a combined numerical and experimental investigation”, Proc. Instn. Mech. Engrs, Part D: J. Automobile Engng., 2011, 225(7), pp.885-894.

[11] Kim, S.J. and Lee, S.K., "Experimental identification of a gear whine noise in the axle system of a passenger van”, Int. J. Automotive Technol., 2007, 8(1), pp. 75-82

[12] Menday, M.T., Rahnejat, H. and Ebrahimi, M. "Clonk: An onomatopoeic response in torsional impact of automotive drivelines”, Proc. Instn. Mech. Engrs, Part D: J. Automobile Engng., 1999, 213 (4), pp.349-357.

[13] Theodossiades, S., Gnanakumarr, M., Menday, M.T. and Rahnejat, H. "Mode identification in impact-induced high-frequency vehicular driveline vibrations using an elasto-multi-body dynamics approach”, Proc. Instn. Mech. Engrs, Part K: J. Multi-body Dyn., 2004, 218(2), pp. 8194. 
[14] Litvin, F. L. and Fuentes, A. Gear Geometry and Applied Theory, $2^{\text {nd }}$ ed., Cambridge University Press, New York, 2004.

[15] Simon, V., "Load Distribution in Hypoid Gears”, Trans. ASME, Journal of Mechanical Design, 2000, 122, pp. 529-535

[16] Simon, V., "FEM stress analysis in hypoid gears", Mechanism and Machine Theory, 2000, 35, pp. 1197-1220

[17] Vijayakar, S. Tooth Contact Analysis Software: CALYX, Advanced Numerical Solutions, Hilliard, OH, 1998

[18] Greenwood, J. A. and Tripp, J. H. “The contact of two nominally flat rough surfaces”, Proc. Instn. Mech. Engrs, 1970-71. 185, pp. 625-633

[19] Rahnejat, H., Multi-Body Dynamics: Vehicles, Machines and Mechanisms, Professional Engineering Publishing (IMechE), UK and Society of Automotive Engineers, Pa, USA (joint publishers), 1998

[20] Gillespie, T. D. Fundamentals of Vehicle Dynamics, Society of Automotive Engineering, Inc. Pa, USA, 1992

[21] Evans, C. R. and Johnson, K. L. "Regimes of traction in elastohydrodynamic lubrication”, Proc. Instn. Mech. Engrs., 1986, 200 (C5), pp. 313-324

[22] Gohar, R. and Rahnejat, H., Fundamentals of Tribology, Imperial College Press, London, 2008

[23] Crook, A. W., "The lubrication of rollers III: A theoretical discussion of friction and the temperatures in the oil film”, Proc. R. Soc. Lond. ,1961, 254 (1040), pp. 237-258

[24] Johnson, K. L. and Greenwood, J., “A. Thermal analysis of an Eyring fluid in EHD traction”, Wear, 1980,61, pp. 353-374.

[25] Chittenden, R. J., Dowson, D., Dunn, J. F. and Taylor, C. M., “A theoretical analysis of the isothermal elastohydrodynamic lubrication of concentrated contacts. II. General Case, with lubricant entrainment along either principal axis of the Hertzian contact ellipse or at some intermediate angle“, Proc. Roy. Soc., Ser. A, 1985, 397, pp. 271-294

[26] Teodorescu, M., Taraza,D., Henein, N. A., and Bryzik,W. "Simplified elasto-hydrodynamic friction model of the cam - tappet contact.” Trans. SAE, J. Engine., 2003, pp. 1271-1283 
[27] Naruse, C., Haizuka, S., Nemoto, R. and Umezu, T.,“Limiting loads for scoring and frictional loss of hypoid gear”, Bull. JSME, 1986, 29(253), pp. 2271-2280

[28] Buckingham, E., “Efficiencies of Gears” in Analytical Mechanics of Gears, Dover, New York, 1963, pp. 395-425.

[29] Xu, H., Kahraman, A. and Houser, D.R., “A model to predict friction losses of hypoid gears”, AGMA Tech. Pap.: 05FTM06, 2005

[30] Hurley, J., "The contact of two nominally flat rough surfaces”, MSc thesis, Ohio State University, 2009. 